\title{
Development of a Tool to Analyze the Economic Viability of Energy Communities
}

\author{
Fernando Carreras* (D) and Gerald Steinmaurer (D) \\ University of Applied Sciences Upper Austria, Energy Research Group ASIC, Wels, Austria
}

Received: 28 June 2021 / Received in final form: 22 July 2021 / Accepted: 4 August 2021

\begin{abstract}
Energy Communities (EC) are an instrument to improve the efficiency and autarky of Smart Grids by increasing the local consume of the energy locally produced. Energetic (energy flows, $\mathrm{CO}_{2}$ emissions) and economic (operative costs, acquisition and maintenance of technologies) aspects of all components of the EC must be evaluated to quantify the participation of the EC to achieve the proposed goal. Effective analysis of EC must account for numerous complexities and uncertainties, requiring advanced computational tools. The main contribution of this paper is the introduction of a software package to analyze the viability of ECs focused on the particularities imposed by the new Austrian law for renewable energies, which optimizes the energy flows between all participants. The results of the test case show more than a $14.2 \%$ reduction of global cost. At the same time, all participants achieve better results operating inside of the EC than alone. The range of cost reductions varies between $2.75 \%$ and $51 \%$. The spread of these reductions opens a question about a fair and optimal way to set trade prices inside of the EC for future works.
\end{abstract}

\section{Introduction}

The Austrian government set recently as goal to cover $100 \%$ of the Austrian electricity consumption in 2030 from renewable energies [1]. Energy Communities (EC) are an instrument to achieve this goal by increasing the local consume of the energy locally produced and hence to increase the efficiency and autarky of grids. Energetic (energy flows, $\mathrm{CO}_{2}$ emissions) and economical (operative costs, acquisition and maintenance of technologies) aspects of an EC must be evaluated to quantify the participation of the EC to achieve the proposed goal.

We programmed a software tool based on Mixed Integer Linear Programming (MILP) to evaluate the economic and energetic viability of a potential EC. Different software tools are already programmed to regulate and control micro and smart grids [2-6] but this new development covers the gap of the particularities imposed by [1] on ECs. In this sense, the software takes into account not only the different roles and parameters of the participants of the EC (producers and/or consumers, private/industry, constant/dynamic prices) and the installed technologies (photovoltaic, solar heat, heat pumps, electric batteries, heat water puffers, ab- und adsorption chillers, etc.) but also the particularities of [1].

\footnotetext{
* e-mail: fernando.carreras@fh-wels.at
}

Most of the usual tools above mentioned, make use of data reduction methods (by instance, by defining one pattern working and weekend day for each month and extrapolating the results along the month) or mean aggregation of time steps of energy loads and generation (considering then one-hour data instead 15-minutes data). Although these methods speed up the computations, our tool is based on a screen moving strategy, which analyses the EC by generating optimisation strategies each 15 minutes for the next 48 hours. This procedure introduce several advantages: it allows considering dynamic buy and selling prices of energy inside and outside of the EC, storage devices can be continuously used, and a higher time resolution provides a more realistic performance of the EC.

The first part of this paper describes the formulation to model the EC and its energy flows as an MILP problem. In a second section, the environment and data for the experimentation are introduced. The third part, presents the results of a practical case. The paper closes with a discussion and plans for future development.

\section{EC modelling}

An EC is considered in its general form as the composition of three levels, corresponding to one kind of energy: electricity, heal and cool. At each level belong all energy sources, which do not require any transformation 


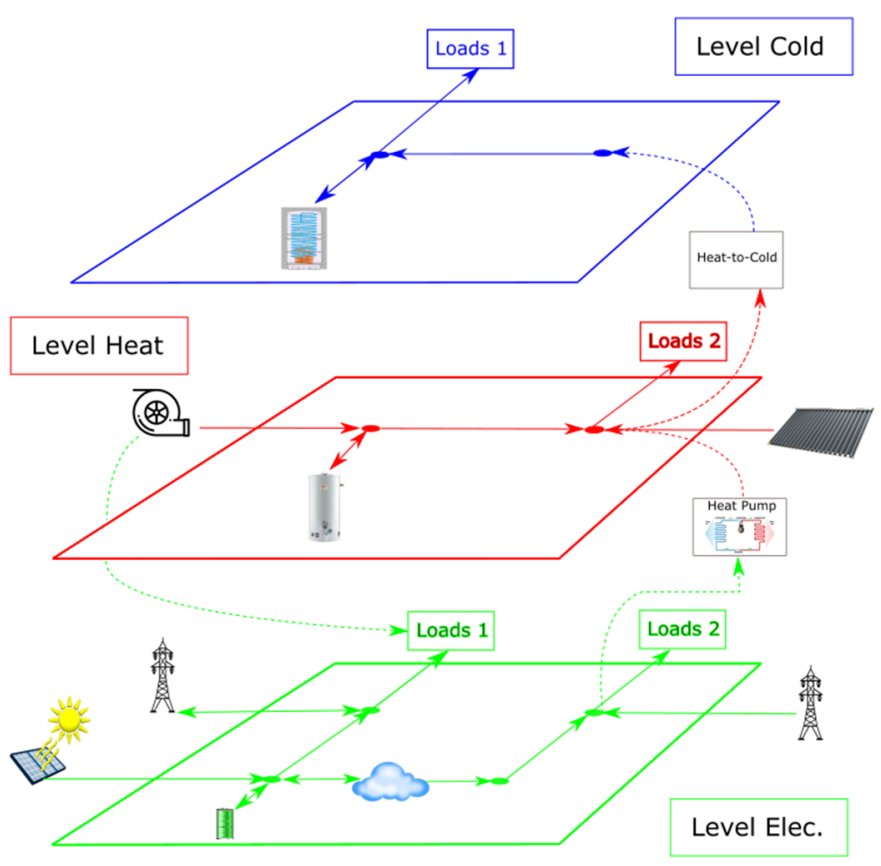

Fig. 1. Scheme of a two-participants EC.

(photovoltaic, wind, geothermal) and storage technologies. Transformation operators represent sector coupling technologies (heat pump, absorption chiller). Each participant can be connected to a public grid and to the grid of the community, to share energy. Members of the community are only allow to sell self-generated energy. For this reason, each participant is modelled mean two nodes. The first node bundles the public grid, loads and energy flows from the second node. This one connects the generators of renewable energies with storage components, community exchange. Both nodes are connected, however in an only one-way (from second to first node) kind, because only energy from renewable sources are allowed to be feed in to the public grid and energy from the public grid does not flow into the community grid. A schema of this construction is illustrated in Figure 1.

In a close way to [5], a mathematical description of the optimization problem is based on balance equations (1), (2) for each node; capacity constrains (3), (4), (5) and storage continuity constraints (6). The objective function to minimize can be in terms of costs and/or emissions defined.

$$
X_{k, \text { in }}^{(1)}(t)-X_{k, \text { out }}^{(1)}(t)=L_{k}(t)
$$

where $X_{k, i n}^{(n)}(t)$ refers to the input flow of energy $k$ at time $t$ for the node $n, X_{k, \text { out }}^{(n)}(t)$ refers to the output flow of energy $k$ at time $t$ for the node $n, L_{k}(t)$ is the load of the $k$ energy time $t$.

$$
G_{k, g}(t)+S_{k, \text { in }}(t)-S_{k, \text { out }}(t)+X_{k, \text { in }}^{(2)}(t)-X_{k, \text { out }}^{(2)}(t)=0
$$

where $G_{k, g}(t)$ refers to the provided $k$ energy by generator/ source $g$ at time $t, S_{k, \text { in }}(t)$ and $S_{k, \text { out }}(t)$ are the input and output flows of energy $k$ at time $t$.

$$
\begin{gathered}
G_{k, g}(t) \leq G_{\max , k, g}(t) \\
X_{k}^{(1)}(t) \leq X_{\max , k}^{(1)}(t) \\
X_{k}^{(2)}(t) \leq X_{\max , k}^{(2)}(t) \\
S O C_{k}(t)=S O C_{k}(t-1)+\eta_{k, \text { ch }} \cdot S_{k, \text { in }}(t)-S_{k, \text { out }}(t) / \eta_{k, \text { dis }}=0
\end{gathered}
$$

where $S O C_{k}(t)$ is the state of charge of storage $k$ at time $t$. Finally $\eta_{k, c h}$ and $\eta_{k, d i s}$ are the charging and discharging efficiencies of the storage system.

The evaluation of the community comprises two stages. The first stage regards the individual-case of each participant alone with the technologies to be installed but any energy exchange with the participants of the EC takes place. At this stage, the energy flows $X_{k, i n}^{(n)}(t)$ and $X_{k, \text { out }}^{(n)}(t)$ are limited to connections of the considered participant. With the information of the equations (1)-(6) one can define the optimization problem for the $i$ participant (7):

$$
\min _{\bar{x}_{i} \in \Omega\left(\bar{x}_{i}\right)} f_{i}\left(\bar{x}_{i}\right)\left\{\begin{array}{l}
A_{e q, i} \cdot \bar{x}_{i}=b_{e q, i} \\
\bar{x}_{l b, i} \leq \bar{x}_{i} \leq \bar{x}_{u b, i}
\end{array}\right.
$$

This optimization problem is solved by using MILP methods for each participant and its solution (costs and/or emissions) provides the reference values for the third stage. For EC with $N$ participants:

$$
V=\left\{v_{1}, v_{2}, \ldots, v_{N}\right\}
$$

with these values will be defined a new optimization problem (second stage), which incorporates these values as a new constraint $b_{\text {ineq }}$ :

$$
\min _{\bar{x} \in \Omega(\bar{x})} f(\bar{x})\left\{\begin{array}{l}
A_{e q} \cdot \bar{x}=b_{e q} \\
A_{i n e q} \cdot \bar{x} \leq b_{i n e q} \\
\bar{x}_{l b} \leq \bar{x} \leq \bar{x}_{u b}
\end{array}\right.
$$

This second optimization considers the whole EC and the new constraint $b_{\text {ineq }}$ guaranties that each participant of the EC profits by the cooperation inside of the community.

Relevant parameters to analyse the community are the time to analyse, the time resolution and the time forecast. These parameters depend on the available data measurements. In practical cases, a whole optimization (both stages) is carried out once each 15 minutes. It provides a control strategy for a time horizon of 24 hours. In addition, to avoid seasonal effects, the time to analyse used to be one or more whole years. Additional parameters to take into account are the sell and buy prices of the public and community grids. 


\section{Environment and data}

The new law for renewable energies in Austria encourages municipalities to cooperate to achieve the objectives. Aspects of this cooperation are divers. From one part, public institutions should provide roof surfaces from public buildings (schools, town halls, sport halls, and gymnasiums) to install new PV panels. On the other hand, installations of technologies to produce renewable and sustainable energies are promoted and financial supported.

Considered Participants are private citizens, the municipality and industrial partners. Prices are different for small and big consumer. Some of the participants are consumers and at the same time energy producers. In a first approach, we have considered an EC with only electricity exchange (heating and cooling loads are carried out by Power to Heat (P2H) and Power to Cool (P2C) technologies and hence they are integrated as electric loads).

Based on realistic values of energy loads [7] and productions [8] in central Europe, we evaluate the economic and energetic viability of an EC composed by 10 participants placed in a medium size rural town under the constraints and rules [1] pointed out at previously. The analysis was carried out with a 15-minutes time resolution and it covers one year.

Table 1 summarizes the parameters of the EC, the planned dimension of PV to be installed, the currently electricity consumption per year and the type of consumer. Electricity prices for private participants $(\mathrm{P})$ and for industrial participants (I) are showed in Table 2. Sell price

Table 1. Description of the participants of the Energy Community.

\begin{tabular}{lcll}
\hline Participant & $\begin{array}{l}\text { PV to } \\
\text { Install } \\
(\mathrm{kWp})\end{array}$ & $\begin{array}{l}\text { Yearly } \\
\text { Consumption } \\
(\mathrm{kWh})\end{array}$ & $\begin{array}{l}\text { Consumer } \\
\text { Type }\end{array}$ \\
\hline 1 & 98 & 523953 & $\mathrm{P}$ \\
2 & 196 & 435599 & $\mathrm{I}$ \\
3 & 100 & 78039 & $\mathrm{P}$ \\
4 & 140 & 85233 & $\mathrm{P}$ \\
5 & 30 & 31255 & $\mathrm{P}$ \\
6 & 63 & 10754 & $\mathrm{P}$ \\
7 & 230 & 31535 & $\mathrm{P}$ \\
8 & 0 & 413820 & $\mathrm{I}$ \\
9 & 0 & 823514 & $\mathrm{I}$ \\
10 & 0 & 229256 & $\mathrm{P}$ \\
\hline
\end{tabular}

to feed the public grid is the same for private and industrial participants and it is regulated by the Abwicklungsstelle für Ökostrom AG [9]. The current value of the compensation is $7.67 € \mathrm{Cent} / \mathrm{kWh}$ but it will be reduced for new contracts to $7.06 € \mathrm{Cent} / \mathrm{kWh}$. The trade prices inside of the EC are only one $€$ Cent/kWh lower (buy price) and one $€$ Cent/kWh higher (sell price) that the respectively prices of the public grid. These prices are set with the only purpose to show, how a one Cent variation is able to produce a reduction of the global costs inside of the EC. With these prices is guaranteed that the producers sell electricity into the EC first and they feed the public grid later.

\section{Results}

Table 3 shows a summary of the yearly results. Three situations are considered for each participant: the current yearly costs without PV, the costs with PV but without collaboration with the community and the costs inside of the community.

The installation of PVs supposes for the participants a costs reduction of a $19.5 \%$. With respect to the current situation, the EC achieves a global costs reduction of $41.6 \%$. The collaboration inside of an EC supposes a winwin situation for all participants: electricity producers are getting an advantageous price by selling electricity into the community and all consumers are paying less by buying electricity from other participants.

Figure 2 shows on the positive part of the diagram the monthly consumption of electricity of the EC (bought from grid, self-consumed and bought inside of the EC) and on the negative part of the diagram, the sold electricity (sold to the EC and sold to grid). Seasonal effects of electricity production are clearly visible. The EC always buys electricity from the public grid because of the nature of PV production. The EC must always sell electricity to the public grid because the consumption of industrial participants sinks on weekends.

As the objective of an EC is to increase the local consumption of locally produced energy as much as possible, a first analysis of the results suggest a potential improvement of the use of the produced energy for the suggested EC. From one part, the use of energy storage technologies could increase the local autarky of the EC. However, the investment costs of such technologies (for the currently subventions policy in Austria these technologies are not the first priority) compared with the potential benefits should be investigated. Another possible explanation for the excess could be an oversized PV production.

Table 2. Buy and sell prices for each consumer type.

\begin{tabular}{lllll}
\hline Consumer Type & $\begin{array}{l}\text { Buy Grid } \\
(€ / \mathrm{kWh})\end{array}$ & $\begin{array}{l}\text { Sell Grid } \\
(€ / \mathrm{kWh})\end{array}$ & $\begin{array}{l}\text { Buy Community } \\
(€ / \mathrm{kWh})\end{array}$ & $\begin{array}{l}\text { Sell Community } \\
(€ / \mathrm{kWh})\end{array}$ \\
\hline Private $(\mathrm{P})$ & 0.16 & 0.0706 & 0.15 & 0.0806 \\
Industry $(\mathrm{I})$ & 0.13 & 0.0706 & 0.12 & 0.0806 \\
\hline
\end{tabular}


Table 3. Summary of results.

\begin{tabular}{lccc}
\hline Participant & $\begin{array}{c}\text { Current Costs } \\
(€ / \text { year })\end{array}$ & $\begin{array}{c}\text { Costs alone } \\
\text { player }(€ / \text { year })\end{array}$ & $\begin{array}{c}\text { Costs Community } \\
\text { player }(€ / \text { year })\end{array}$ \\
\hline 1 & 83832.5 & 64578.8 & 62801.9 \\
2 & 566627.9 & 35750.7 & 29992.6 \\
3 & 12486.2 & 2888.9 & 1703.5 \\
4 & 13637.3 & -2130.1 & -3218.3 \\
5 & 5000.9 & 1673.8 & 1323.9 \\
6 & 1720.7 & -3520.2 & -3681.8 \\
7 & 5045.7 & -13172.6 & -13797.1 \\
8 & 53796.7 & 53796.7 & 3601.3 \\
9 & 107056.9 & 107056.9 & 85814.2 \\
10 & 36681.1 & 36681.1 & 34354.2 \\
Global costs $(€ /$ year $)$ & 375885.9 & 302426.9 & 219591.6 \\
\hline
\end{tabular}

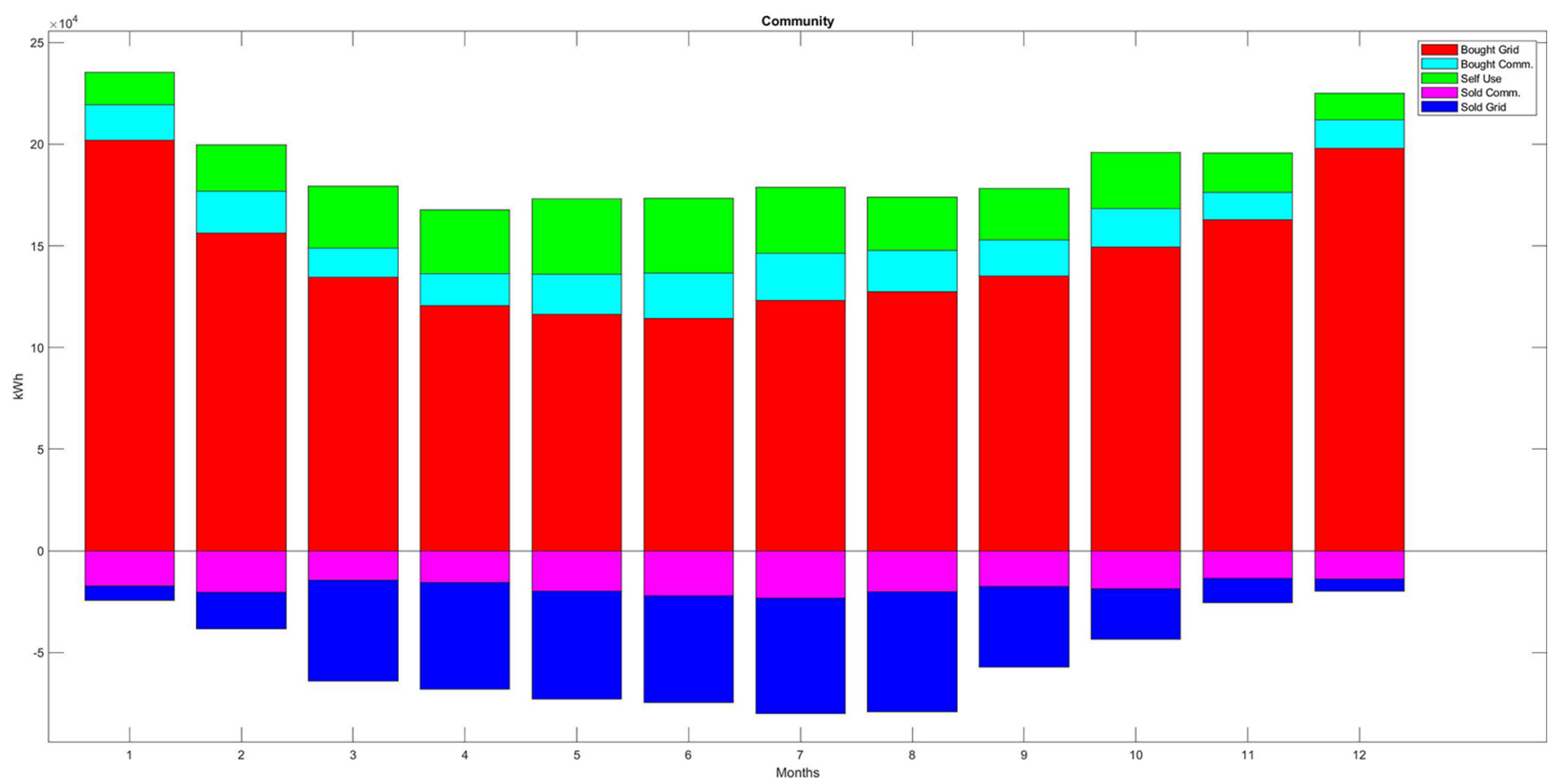

Fig. 2. Monthly distribution of the electricity consumption.

An EC can be considered from the point of view of grid operators as an instrument to stabilize the grid at regional and national levels. For this reason, the implementation of storage technologies and its consequences must be considered not only at the level of the EC.

\section{Conclusion and future work}

In this paper, a new software tool for analysis of EC focused on the restrictions of the new Austrian law for renewable energies was presented. It was shown that this tool is able to manage heterogeneous configurations of participants attending to the played roles and their nature as consumer.
The tool provides not only economic results but also analyses of the energy flows, which help to identify possible improvements by the configuration of the EC.

The tool was tested with realistic parameters for the Austrian case and with a difference of only $0.01 € / \mathrm{kWh}$ between the trade prices of public and community grids, the cooperation between all the participants achieves a global costs reduction of a $14.2 \%$.

ECs seem to be a promising way to achieve the objectives set by the new Austrian law of renewable energies. For this reason, future extensions of the software tool plan to extend the integration of transformation technologies for sector coupling and the incorporation of new participation forms such as mobility (Vehicle to Grid or Vehicle to Community). 
The software tool is able also to handle dynamic buy and sell prices for each participant. This feature was not used at the current experimentation because it has to do with an open question: how can one establish fair trade prices inside of the community? As the participants of the EC are involved with different investments, the prices should be set in a way that these economic efforts must be somehow compensated. Future research is here needed.

Acknowledgments. This paper and the research behind it would not have been possible without the exceptional financial support of the Government of Upper Austria through the project FTI-OÖ Förderung Energieforschung FH OÖ - Methodenentwicklung für Energieflussoptimierung.

\section{References}

1. Erneuerbaren-Ausbau-Gesetz - EAG; Erneuerbaren-Ausbau-Gesetzespaket - EAG-Paket (58/ME), (2020), https:// www.parlament.gv.at/PAKT/VHG/XXVII/ME/ME_00058/ index.shtml
2. L.A. Bollinger, V. Dorer, The Ehub Modelling tool: a flexible software package for district energy system optimization, Energy Proc. 122, 541-546 (2017)

3. E. Grover-Silva, M. Heleno, S. Mashayekh, G. Cardoso, R. Girard, G. Kariniotakis, A stochastic optimal power flow for scheduling flexible resources in microgrids operation, Appl. Energy 229, 201-208 (2018)

4. J. Iria, M. Heleno, G. Cardoso, Optimal sizing and placement of energy storage systems and on-load tap changer transformers in distribution networks, Appl. Energy 250, 1147-1157 (2019)

5. R. Evins, K. Orehounig, V. Dorer, J. Carmeliet, New formulations of the 'energy hub' model to address operational constraints, Energy 73, 387-398 (2014)

6. R. Evins, Multi-level optimization of building design, energy system sizing and operation, Energy 90, 1775-1789 (2015)

7. BDEW Media. https://www.bdew.de/energie/standardlast profile-strom/. Last visited 24.03.2021

8. https://www.velasolaris.com/software/

9. OeMAG Abwicklungsstelle für Ökostrom AG, www.oemag.at

Cite this article as: Fernando Carreras, Gerald Steinmaurer, Development of a Tool to Analyze the Economic Viability of Energy Communities, Renew. Energy Environ. Sustain. 6, 28 (2021) 